\title{
Crowdfunding for Financing Wearable Technologies
}

\author{
Fehmi Tanrisever \\ Faculty of Business Administration, Bilkent \\ University, 06800 Ankara, Turkey, \\ tanrisever@bilkent.edu.tr
}

\begin{abstract}
We explore electronic crowdfunding platforms as a means of receiving money and other resources by an entrepreneur from many parties for financing wearable technology project. The electronic platform determines the cost of funding for the entrepreneur and the return investors will receive per period. This research aims to develop a framework to understand and evaluate the quantitative and qualitative implications of various crowdfunding platforms for the entrepreneur and his investment decisions in wearable technologies. We consider a debt financing based platform and examine its operational implications on the entrepreneur's decisions. In addition, we identify the incentive problems that occur in these models.
\end{abstract}

\section{Introduction}

After the recent financial crises, banks have developed a reluctance to provide financing to entrepreneurs. The banks are even more reluctant to finance wearable technology projects due to the high market and technology risks associated with them. In order to overcome this problem, entrepreneurs are seeking alternative ways to obtain funding. As a result, crowdfunding is becoming increasingly popular as a means of new venture financing especially for high risk wearable technologies.

For example recently, doppel (a performanceenhancing wearable technology) managed to successfully raise more than $£ 110.000$ from 820 backers through crowdfunding. Similarly, PUGZ (world's smallest wireless earbuds charged through phone) has already raised $\$ 300.000$ through the Kickstarter. As of September 2015, there are 33 wearables projects actively raising funds on Kickstarter through crowdfunding. In general, crowdfunding is viewed as a common financing mechanism to finance high risk wearable technology projects.

\author{
Karen-Ann Wismans - Voorbraak \\ Koninklijke Ahold N.V., 5600BG Eindhoven, The \\ Netherlands, \\ karen-ann.voorbraak@ahold.com
}

Crowdfunding is not new; it has been the backbone of the American political system for a long time $[1,2]$. According to [3], raising funds by tapping general public is the key element of crowdfunding. The idea of crowdfunding is to obtain funding from a large audience, where each individual provides a small amount, instead of raising the money from a very small group of sophisticated investors. Entrepreneurs are not only motivated to use crowdfunding for obtaining funding; they also use it for acquiring information [4]. Hence, crowdfunding can be employed as a way of promoting the company, to support user-based improvement, or as a way for the producer to be better informed about the preferences of the consumer. In that sense, it is an excellent tool for co-creation, in which both firms and active customers create value through new forms of interaction, service and learning mechanisms. The meaning of value and the process of value creation are rapidly shifting from a product- and firm-centric view to personalized consumer experiences [5]. This is in line with [3], who focus specifically on crowdfunding and state that investors do not only participate in crowdfunding projects because they have extrinsic motivations (monetary reward), but they also have intrinsic motivations (related to the pleasure or fun of doing the particular task i.e. investing). In this research, crowdfunding is defined as follows:

"Crowdfunding is the process of one party requesting and receiving money and other resources from many parties for financing a project, in exchange for a monetary or non-monetary return or for a charitable reason."

More specifically, [1] evaluates three typical examples of crowdfunding to explain the concept: peer-to-peer micro lending websites, funding art (books, music, etc.) and funding starting companies. The first example is peer-to-peer micro lending websites like Kiva, where people can directly lend money to small businesses in the Third World. Kiva is a platform that uses the Internet to connect small businesses in the Third World with philanthropically 
minded lenders in the First World. Second, websites like Sellaband and TenPages are set up to support upcoming artists or writers by providing funding for the production of an album or publication of a book. Third, the crowd can fund a whole company or project executed by an entrepreneur. Entrepreneurs obtain money from the crowd to fund a concrete project with financial needs, via websites like Kickstarter.

This research will focus on the third type of crowdfunding: funding new ventures. [3] consider crowdfunding as an interesting alternative for traditional financing methods like debt and equity financing. This research will elaborate on this observation. However, crowdfunding may be offered in a debt or equity structure itself.

In crowdfunding, the entrepreneur makes an open call for funding a new venture or other project on an electronic platform. The entrepreneur offers the investors a return on their investment, which may be both a monetary return and/or a non-monetary return ("in-kind"). He sets the return beforehand. The monetary return depends on the revenues of the venture and is constrained by a minimum of zero and a particular maximum value. The in-kind reward depends on the product or service that the entrepreneur offers, like a free sample of the product. In addition to the obligation of paying the investor a return, the entrepreneur is compulsory to inform the investor about his progression and financial statements.

The second stakeholder is the group of investors. In the Netherlands, the investor is by law allowed to invest an amount between $€ 10$ and $€ 5,000$ per venture, and in total not more than $€ 40,000$, allocated over a maximum of 100 ventures.

Third, the platform plays a central role. The platform facilitates the crowdfunding process by bringing together entrepreneurs and investors and assisting in the conclusion of an agreement between investor and entrepreneur. The platform also assists the entrepreneur in the fulfillment of his contractual obligations and coordinates the cash flow from investor to entrepreneur via a blocked bank account.

The crowdfunding process can been divided in three phases: the pre-crowdfunding-period, the crowdfunding-period, and the post-crowdfunding period. In the pre-crowdfunding-period, the platform screens entrepreneurs, they both sign a contract and together they determine the variables that define the financial structure.

Subsequently, the crowdfunding period starts. During the crowdfunding phase, investors pay an amount between $€ 10$ and $€ 5,000$ into a third party account. Crowdfunding platforms typically work with a minimum pledge: when the entrepreneur attains a threshold amount, he obtains his money, otherwise he does not. All payments are voided unless a minimal amount is reached before some deadline. If the total amount that is paid by investors is smaller than the amount required by the entrepreneur as determined beforehand, investors receive their investment back, minus transaction costs. On the other hand, if the entrepreneur has collected the threshold amount, he receives the amount minus a success fee. As a result, he sets up his business and the post-crowdfunding period begins. Within this phase, the entrepreneur yearly pays a particular return to the investors, which is based on yearly revenues and constrained by a predefined maximum.

Along the crowdfunding process, three important decision making points for the platform can be identified. First, the platform needs to decide which entrepreneurs to accept on the platform and which not. However, this decision is affected to a large extent by legal restrictions. The platform is not allowed to select entrepreneurs, because they are legally not allowed to provide investors with advice. However, to prevent swindlers from getting access to the platform, the platform has drawn up several objective criteria, which should be met by the entrepreneur. The entrepreneur should for instance be able to open a business bank account.

Second, the platform limits the crowdfunding period and determines the exact duration of this period.

Third the platform specifies the financial structure, i.e., the return investors will receive per time period.

This research aims to develop a quantitative framework to understand and evaluate the implications of various crowdfunding models for the entrepreneur and investors. A detailed understanding of crowdfunding is crucial for designing the crowdfunding process in an optimal way. This research will mainly focus on the financial structure once the entrepreneur has collected his money, which determines the financial return to the investor. An optimal financial structure is essential in order to keep all three stakeholders involved in the long term. Insight in the various forms of financial models is of main importance for a crowdfunding platform that needs to choose for a particular financial model. Besides, this knowledge will provide the entrepreneur with understanding of the consequences of choosing a particular crowdfunding platform.

\section{Literature Review}


Crowdfunding finds its roots in crowdsourcing (1, 6 , 7] the raise of crowdsourcing explains the popularity of crowdfunding. Crowdsourcing is the general phenomenon in which firms outsource tasks that are traditionally performed by their employees to people who use their own time to complete these tasks. Hence, people use crowdsourcing to obtain ideas, feedback and solutions from the "crowd". The crowd is usually but not necessarily reached through the Internet or social media. Jeff Howe in June 2006 first mentioned the word "crowdsourcing" in Wired Magazine. He defines crowdsourcing as follows.

"Crowdsourcing is the act of a company or institution taking a job traditionally performed by a designated agent (usually an employee) and outsourcing it to an undefined, generally large group of people in the form of an open call."

[1] states that crowdsourcing, and thus also crowdfunding, has emerged for four reasons. (1) As a result of the specialization of jobs, private individuals are interested in contributing to economic production in their spare time to do something different for a change or because they are willing to share their knowledge. (2) Dividing an overwhelming task into small enough chunks makes completing it not only feasible, but fun. See for example the open source software trend in the software industry (3) Increasing accessibility of information. (4) Emergence of online communities in which the online population is organized. The Internet allows for communication between amateurs and professionals. Where once professionals were in power, now a self-organizing community of amateurs takes on a large extent of the labor.

These four reasons seem to apply to crowdfunding as well. Concerning the second reason, the small chunks can be compared to the small amounts that investors provide individually. In addition, [3] state that the risk taken by investors might be smaller than in traditional venture financing methods, because a member of the crowd may become a consumer once the product has been brought to the market. Besides the investors have an incentive to spread the information about the product if they participate in the profit of the venture; they benefit when their network buys the product. As a result, crowdfunding may be used for e-marketing as well.

Other authors also endorse the importance of online communities. [8] show that social ties provide an important mechanism through which information asymmetry is overcome in venture finance in general. [9] identifies crowdfunding as an approach used to stream joined good will efforts of people; the option that community members have to invite each other for giving funding is an important trigger to donate. [10] model the importance of peer effects on the contributions in crowdfunding. They claim that the number of investors that has already invested is an indication of the probability of success for potential investors.

In conclusion, crowdfunding seems to be a subset of the more general concept of crowdsourcing. However, practically, crowdfunding is more difficult to implement because of various legal, technical and social complexities $[6,3]$. Important legal limitations occur, if it involves the offering of equity to the crowd, because making a widespread solicitation for equity offering is limited to publicly listed equity. As a result of legal limitations, the crowdfunding participation is often structured in the form of making the participating crowd a member instead of a shareholder. Second, problems may be caused by information asymmetry, a topic that will be evaluated later on. Investors are not specialists and thus have access to less information about the industry, past performance of the entrepreneur and many other pieces of relevant information. Idea stealing may further be of concern, since the entrepreneur needs to disclose appropriate information to a wider audience than under traditional forms of fundraising. On the contrary, other information problems that exist in traditional venture finance are solved for crowdfunding.

Not much research has been executed on modeling crowdfunding in particular. However, attempts of modeling crowdsourcing and crowdfunding are discussed subsequently. Several models have been developed to illustrate crowdsourcing, both with risky return [10,11,12,13] and guaranteed return [14]. When comparing these models to crowdfunding, the risky return models seem to be more applicable, because the investors may not always get repaid their money. [10] and [11] have modeled crowdsourcing as an auction, but this does not seem to be a useful instrument because the return provided to investors by crowdfunding is unknown in advance. The return does not only depend on the investor's own efforts but also on revenues; the efforts of the entrepreneur.

[10] and [11] have used game theoretic tools for modeling crowdsourcing. Furthermore, [6] has used those tools for modeling crowdfunding as well. He has developed a model in which interdependent agents operate in a dynamic, discrete setting. Potential investors decide whether to invest in passive investment, active investment, donation or whether they should wait for the next period. Moreover, he approaches the topic from investor's 
perspective and focuses on the process of money collection: earlier defined the crowdfunding period.

In addition, [4] identify a number of issues related to crowdfunding that are worth studying from an industrial organization perspective. Besides, they propose some preliminary efforts towards modeling crowdfunding. In their model, they associate crowdfunding with pre-ordering and price discrimination and they identify crowdfunding as an entrepreneur's attempt to inform consumers of their product's value. The trade-off that is explored is the following: with respect to external funding, crowdfunding has the disadvantage of delaying profit by one period and the advantage of offering an improved product to some consumers. In contrast, one would expect that investors invest mainly for receiving financial return and for the fun of being involved, and not especially for improving the final product.

In conclusion, there is a gap in literature in terms of a modeling framework to provide precise assessment of the post-crowdfunding period in particular.

\section{Methodology}

In this chapter, the methodology and terminology are introduced. Several assumptions that are applicable to the framework are described and justified below.

Assumption 1: The venture is completely financed by crowdfunding.

The venture is completely financed by debt-based crowdfunding: no other variants are possible. Besides, the entrepreneur does not have other sources of funding.

Assumption 2: The fixed startup costs are zero.

For simplicity, fixed startup costs are normalized to zero. However, the results trivially extend to the case with fixed startup costs lager than zero.

Assumption 3: No taxes.

As stated earlier, in the debt case the entrepreneur may have tax benefits on interest paid. Other authors, like [15], do consider tax benefits of debt on production decisions. However, tax is not a main issue in this research, and including them will make it unnecessarily complicated.

Assumption 4: The only variable that the entrepreneur can affect is the production quantity.

At the beginning of each period, the entrepreneur determines which quantity $q_{t}$ to produce, while taking into account forecasted demand as market size $\theta$ and the production costs per unit $c$. This is the only decision that the entrepreneur makes in the models.
Although in practice the entrepreneur can engage in a variety of activities, which generate profit and costs, like choices about markets, organization and innovation [15], those choices will not be taken into account.

Assumption 5: The price of the product is assumed to be defined by a linear inverse demand function of the entrepreneur's product [17].

The price of the product is defined by a linear inverse demand function:

$$
p_{t}\left(q_{t}, \tilde{\varepsilon}_{t}\right)=\theta-q_{t}+\widetilde{\varepsilon_{t}}
$$

in which $\theta$ represents the market size [17]. To incorporate the implications of stochastic demand in the model, a demand shock $\widetilde{\varepsilon_{t}}$ is introduced in each period $t$, which likewise also affects the price. The demand shock has a normally distributed probability density function $\varphi($.$) , with mean \mu$ and variance $\sigma^{2}$, and cumulative distribution function $\Phi($.$) . The$ demand shocks occur by the end of each time period.

Assumption 6: The only risk that the entrepreneur faces is demand risk.

Although the entrepreneur may also experience technical uncertainty or market uncertainty [18], only demand risk is taken into account because the models focus on operational decisions. The other uncertainties are less important for the scope of this research.

We consider a two-period model and by the end of each period, the entrepreneur realizes revenues from sales. The revenues made after each period are described by:

$$
\widetilde{R_{t}}\left(q_{\mathrm{t}}\right)=p_{\mathrm{t}}\left(q_{\mathrm{t}}, \tilde{\varepsilon}_{\mathrm{t}}\right) q_{\mathrm{t}}=\left(\theta-q_{\mathrm{t}}+\tilde{\varepsilon}_{\mathrm{t}}\right) q_{\mathrm{t}}
$$

As a result, subtracting the production costs from revenues results in the profit in period $t$, given by $\tilde{\pi}_{t}\left(q_{t}\right)$ :

$$
\begin{aligned}
& \tilde{\pi}_{t}\left(q_{\mathrm{t}}\right)=\widetilde{R}_{\mathrm{t}}\left(q_{\mathrm{t}}\right)-c q_{\mathrm{t}}=\left(\theta-q_{\mathrm{t}}+\tilde{\varepsilon}_{\mathrm{t}}\right) q_{\mathrm{t}}-c q_{\mathrm{t}} \\
& \tilde{\pi}_{\mathrm{t}}\left(q_{\mathrm{t}}\right)=\widetilde{R}_{\mathrm{t}}\left(q_{\mathrm{t}}\right)-c q_{\mathrm{t}}=\left(\theta-q_{\mathrm{t}}+\tilde{\varepsilon}_{\mathrm{t}}\right) q_{\mathrm{t}}-c q_{\mathrm{t}}
\end{aligned}
$$

This profit, however, does not take into account the costs of obtaining funding yet. The final profit for the entrepreneur is affected by those costs. The costs of funding differ per model, and after subtracting those costs, the entrepreneur makes profit $\hat{\pi}_{t}\left(q_{t}\right)$. We aim to formulate a model that can be used to find the optimal production quantity $q_{t}$ that maximizes expected profit for the entrepreneur. The two period model is solved by backwards induction. Hence, the second period optimal production quantity is determined first by solving a simple optimization problem. Using this information, one can determine what amount to produce in the first period.

Assumption 7: The entrepreneur does not have any competitors. 
In addition, it is assumed that the entrepreneur holds a monopoly position in both periods. This seems reasonable, as the entrepreneur identifies and initially exploits an opportunity [18]. As a result, the optimal quantity to produce in the second period is called the monopoly quantity. However, the model can be extended with the occurrence of competition.

We build on a model developed by [19]. We start from their two period model with stochastic demand, and aim to formulate a model that can be used to find the optimal production quantity that maximizes expected profit for the entrepreneur in the debt case. The entrepreneur needs to make debt payments; he pays off the debt with a constant positive interest rate $r$. He should generate a pre-specified level of profit from its operations during the first period to be able to repay his debt and to ensure survival into the second period. Therefore a probabilistic survival constraint is introduced. In the second period, the entrepreneur obtains an additional loan to continue production. In their model, [19] showed that entrepreneurs can respond to bankruptcy risk by creating an operational hedge with its production decisions. For instance, he may produce less than the monopoly quantity in the first period to avoid bankruptcy (underproduction).

The models are maturity based: the entrepreneur pays to investors after a certain time period, and after both periods he has no obligations anymore, no matter how much has been paid. However, also income-based models are possible, in which the entrepreneur pays back to investors up to a particular amount. Nevertheless, those alternatives are not considered in this research.

Our results provide model-based guidelines for the financial repayment structure of a crowdfunding platform. The effect of the following variables is studied: $\theta$ market size, $r$ interest rate, $\beta$ percentage profit/revenues paid, $\underline{\pi} / \underline{R}$ threshold after which entrepreneur starts paying.

\subsection{Mathematical Model}

As stated earlier, we build on a model developed by [19]. We start from their two period model with stochastic demand, and we aim to formulate a model that can be used to find the optimal production quantity $q_{t}$ that maximizes profit $\hat{\pi}_{t}\left(q_{t}\right)$ for the entrepreneur in the debt case.

If the entrepreneur chooses for a bank loan, it is assumed that he gets as much money from the bank as he needs. In the first period, $t=1$, the entrepreneur starts running his business. By the end of the first period, the entrepreneur makes debt payments. If the entrepreneur made sufficient revenues to pay back debt plus an interest rate, he proceeds to the second period, $t=2$.

At the beginning of each period, the entrepreneur determines what quantity $q_{t}$ he will produce, according to his forecasted demand and the production costs per unit $c$. Subsequently, the entrepreneur receives the amount $c q_{t}$ required for production from the bank. The price of the product is defined by a linear inverse demand function: $p_{t}\left(q_{t}, \tilde{\varepsilon}_{t}\right)=\theta-q_{t}+\widetilde{\varepsilon_{t}}$ in which $\theta$ represents the market size (Varian, 2010). To incorporate the implications of stochastic demand in the model, a demand shock $\widetilde{\varepsilon_{t}}$ is introduced in each period $t$. The random variable $\widetilde{\varepsilon_{t}}$ is described by a normally distributed probability density function $\varphi($.$) , with$ mean $\mu$ and variance $\sigma^{2}$, and cumulative distribution function $\Phi($.$) . The demand shocks occur by the end$ of each time period. The revenues made after each period are described by

$$
\widetilde{R}_{t}\left(q_{t}\right)=p_{t}\left(q_{t}, \tilde{\varepsilon}_{t}\right) q_{t}=\left(\theta-q_{t}+\tilde{\varepsilon}_{t}\right) q_{t}
$$

As a result, profit in period $t$, given by $\tilde{\pi}_{t}\left(q_{t}\right)$, can be calculated:

$$
\tilde{\pi}_{\mathrm{t}}\left(q_{\mathrm{t}}\right)=\widetilde{R}_{\mathrm{t}}\left(q_{\mathrm{t}}\right)-c q_{\mathrm{t}}=\left(\theta-q_{\mathrm{t}}+\tilde{\varepsilon}_{\mathrm{t}}\right) q_{\mathrm{t}}-c q_{\mathrm{t}}
$$

Assumption 4.1: Debt is issued at a constant interest rate and upon fully paying its previous debt the entrepreneur can borrow again in the second period to cover its production cost.

Then, the entrepreneur makes debt payments; he pays off the debt with positive interest rate $r$. Hence, the costs of a bank loan for the entrepreneur are given by $r c q_{t}$ in time period $t$.

As a result, profit in period $t$, given by $\tilde{\pi}_{t}\left(q_{t}\right)$, can be calculated:

$$
\begin{aligned}
\hat{\pi}_{t}\left(q_{\mathrm{t}}\right)=\tilde{\pi}_{\mathrm{t}}\left(q_{\mathrm{t}}\right) & -r c q_{\mathrm{t}} \\
& =\left(\theta-q_{\mathrm{t}}+\tilde{\varepsilon}_{\mathrm{t}}\right) q_{\mathrm{t}}-(1+r) c q_{\mathrm{t}}
\end{aligned}
$$

Assumption 4.2: The entrepreneur goes bankrupt and gets liquidated unless he pays debt and interest at the end of each period.

The entrepreneur must generate a pre-specified level of profit from its operations during the first period to ensure survival into the second period. Therefore a probabilistic survival constraint is introduced: the entrepreneur only survives the first period if $\hat{\pi}_{1}\left(q_{1}\right)>\bar{\pi}$. If the entrepreneur defaults, he goes bankrupt and gets liquidated [16].

According to [19], entrepreneurs can respond to the bankruptcy risk, which is caused by demand uncertainty and the probabilistic survival constraint, by creating an operational hedge with its production decisions. Here, operational hedging is defined as employing operational activities to mitigate risk exposure and reduce disadvantageous risk. 
As a result, the value function $V($ ) for the entrepreneur can be expressed as follows:

$$
\begin{aligned}
& V(.)=\max _{q_{1} \geq 0} \mathrm{E}_{\tilde{\varepsilon}_{1}}\left[\hat{\pi}_{1}\left(q_{1}\right)+V_{2}\left(q_{1}, \tilde{\varepsilon}_{1}\right)\right] \\
& \text { s.t. } \hat{\pi}_{1}\left(q_{1}\right) \geq \bar{\pi} \\
& \text { where } V_{2}\left(q_{1}, \tilde{\varepsilon}_{1}\right)=\max _{q_{2} \geq 0} \mathrm{E}_{\tilde{\varepsilon}_{2}}\left[\hat{\pi}_{2}\left(q_{2}\right)\right]
\end{aligned}
$$

The stochastic survival constraint indicates that the firm will go to the second period only if the firm survives the first period $\left(\hat{\pi}_{1}\left(q_{1}\right) \geq \bar{\pi}\right)$. The value of $\bar{\pi}$ is assumed to be non-positive. However, it is not necessarily zero as it depends on the assets of the firm.

There are two scenarios that might occur. First, the entrepreneur may not be able to repay the entire debt; the default scenario. In the second scenario, the entrepreneur makes enough profit to survive the first period and make debt payments; the survival scenario. Two boundaries are defined that ascertain the threshold in which scenario $\tilde{\varepsilon}_{1}$ ends up.

Proposition 4.1: the entrepreneur survives the first period if

$$
\tilde{\varepsilon}_{1} \geq \overline{\varepsilon_{1}}=\frac{\bar{\pi}+(1+r) c q_{1}}{q_{1}}-\theta+q_{1}
$$

Moreover the boundary $\tilde{\varepsilon}_{1}=\overline{\varepsilon_{1}}$ for which the venture survives the first period is obtained by setting $\hat{\pi}_{1}\left(q_{1}\right)=\left(\theta-q_{1}+\tilde{\varepsilon}_{1}\right) q_{1}-(1+r) c q_{1} \geq \bar{\pi}$. If $\tilde{\varepsilon}_{1} \geq \overline{\varepsilon_{1}}$ the entrepreneur survives the first period and he makes profit in both the first and the second period.

Given the normally distributed probability function, the boundary that defines the scenarios can be distinguished as illustrated in figure 2. An example is considered of the probability density function with $\mu=0$ and $\sigma=3$, to investigate the boundaries. The figure illustrates an example for $q_{1}=10$ with $\theta=20, r=0.09, c=6, \bar{\pi}=0$. The area on the left of the red boundary $\overline{\varepsilon_{1}}$ applies to the bankruptcy scenario: the entrepreneur does not survive the first period and he is not able to pay back full debt. The area below $\varphi\left(\tilde{\varepsilon}_{1}\right)$ on the right of $\overline{\varepsilon_{1}}$ applies to the second scenario: $\tilde{\varepsilon}_{1}<\overline{\varepsilon_{1}}$. In this scenario, the entrepreneur survives the first period.

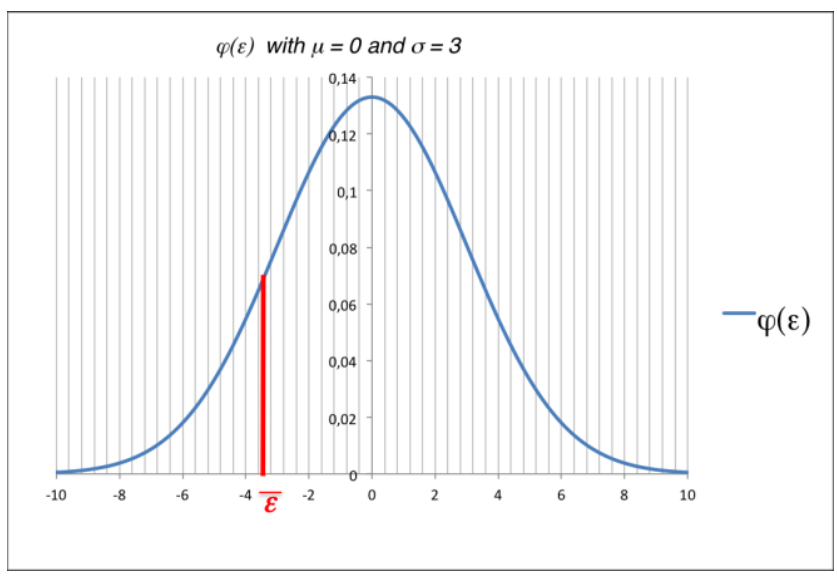

Figure 1 Probability density function and boundary

By solving the two period model, we aim to identify the optimal production quantity that the entrepreneur will produce, based on maximizing expected profit. The problem can be solved by backwards induction, and therefore the second stage problem should be solved first. Consequentially, the solution for the second period can be filled out in the value function $V($ ) . Since there is assumed to be no competition in this situation, $q_{2}=q_{m}=q^{*}$, where $q_{m}$ is the monopoly quantity.

Proposition 4.2: The optimal production level in the second period $q^{*}$ in the debt case is equal to the monopoly quantity $q_{m}=\frac{\theta-(1+r) c}{2}$. The optimal profit in the second period is given by $V_{2}\left(q_{1}, \tilde{\varepsilon}_{1}\right)=\left[\frac{\left(\theta-(1+r j c)^{2}\right.}{4} \mid \tilde{\varepsilon}_{1} \geq \overline{\varepsilon_{1}}\right]$.

The optimal production quantity is found by setting $\frac{d}{d q_{2}} \mathrm{E}_{\varkappa_{2}}\left[\hat{\pi}_{2}\left(q_{2}\right)\right]=0$. Substituting the optimal second period solution into the profit function results in the optimal profit. As a result, the value function for the entrepreneur $V($,$) may also be written as:$

$$
\begin{aligned}
V(.)=\max _{q_{1} \geq 0}\left(\theta-q_{1}\right) q_{1}-(1+r) c q_{1} \\
+\int_{\overline{\varepsilon_{1}}}^{\infty}\left(\frac{(\theta-(1+r) c)^{2}}{4}\right) \varphi\left(\tilde{\varepsilon}_{1}\right) d \tilde{\varepsilon}_{1}
\end{aligned}
$$

This equation is not easily algebraically solved while considering a normal distributed probability density function. However, when assuming a uniformly distributed probability density function, it is solvable. Under a normally distributed probability density we resort to numerical analysis.

In essence, this study has made a first start at modeling the various crowdfunding models that are available to subdivide the benefits of a crowdfunded venture between entrepreneur and investors. The results from this study consist on the one hand of a quantitative framework, which evaluates the 
consequences of various crowdfunding models and several relevant market parameters for the entrepreneur. On the other hand, the results provide model-based guidelines for the financial repayment structure of a crowdfunding platform.

The evaluation of the debt model has showed that increased bankruptcy risk causes the entrepreneur to adopt a conservative operating policy to protect against bankruptcy risk in the first time period. This is in line with the findings of [19] and [15]. This operational hedge against bankruptcy risk does not lead to incentive problems between investor and entrepreneur. For the provider of the loan, survival of the firm is also of main importance to regain his investment.

\section{Conclusions}

This study provides important information for both academics and practitioners. It is valuable for operations management and management information systems literature, because this study considers the influence of capital structure in a crowdfunding environment on the operational decisions of a wearable technology firm. The results confirm findings of authors like [19] and [15], who investigate production decisions in a debt environment under demand uncertainty and market imperfections. Besides, this research is a valuable contribution to literature that is available about crowdfunding.

Besides, the mathematical framework that has been developed is a useful tool that can be used by practitioners in wearable technology business. The models can be used for setting parameters that fix the payoff structure for individual entrepreneurs. In addition, the framework can be used for comparing the financial structures with each other and for determining the expected profit for a particular entrepreneur who desires to obtain funding by crowdfunding. However, increasing the practical applicability of the models contributes to increasing the value for practitioners.

This research has been conducted at ABN AMRO Bank N.V., which currently is developing an online crowdfunding platform that may be used by entrepreneur to finance new ventures. The platform needs to decide what financial model to adopt for paying back investors, and this choice has led to the direction of this research. Namely, feasible design of that financial model has been recognized as of main importance to keep the stakeholders (i.e. entrepreneur and investors) involved in the long term.

The main goal of this research has been defined as developing a quantitative framework to understand and evaluate the implications of various crowdfunding models for the entrepreneur and investors and to provide model-based guidelines. For future research, we believe that it is a fruitful direction to explore models that optimize the interest rate and the bankruptcy thresholds.

\section{References}

[1] Howe, J, Crowdsourcing: How the power of the crowd is driving the future of business, Random House, 2008.

[2] T. Kappel, "Ex ante crowdfunding and the recording industry: A model for the US.", Loy. LA Ent. L. Rev, 2008.

[3] A. Schwienbacher, and L. Benjamin, "Crowdfunding of small entrepreneurial ventures." HANDBOOK OF ENTREPRENEURIAL FINANCE, Oxford University Press, Forthcoming (2010).

[4] P. Belleflamme, T. Lambert, and A. Schwienbacher, "Crowdfunding: Tapping the right crowd", Journal of Business Venturing, 2014, 585-609.

[5] C.K. Prahalad, and V. Ramaswamy, "Co-Creation Experiences: The Next Practice in Value Creation", Journal of Interactive Marketing, 2004, 5-14.

[6] B. J. Rubinton, "Crowdfunding: disintermediated investment banking." Available at SSRN 1807204, 2011.

[7] S.A.M. Geerts, "Discovering Crowdsourcing Theory, Classification and Directions for use.", Master Thesis Eindhoven University of Technology, 2009.

[8] S. Shane, and D. Cable, "Network Ties, Reputation, and the Financing of New Ventures", Management Science, 2002, 364-381

[9] A. Wojciechowski, "Models of Charity Donations and Project Funding of Social Networks.", Lecture Notes in Computer Science, 2009, 454-463.

[10] D. DiPalantino, M. Vojnovic, "Crowdsourcing and All-Pay Auctions", Proceedings of the 10th ACM International Conference on Electronic Commerce, 2009, 119-128.

[11] N. Archak, and A. Sundararajan, "Optimal Design of Crowdsourcing Contests.”, ICIS 2009 Proceedings, 2009.

[12] C. Terwiesch, and Y. Xu, "Innovation Contests, Open Innovation, and Multiagent Problem Solving." Management Science, 2009, 1529-1543.

[13] Tomczak, Alan, and Alexander Brem. "A conceptualized investment model of crowdfunding." Venture Capital, 2013, 335-359. 
[14] J.J. Horton, and L.B. Chilton, "The Labor Economics of Paid Crowdsourcing.", EC '10 Proceedings of the 11th ACM conference on Electronic commerce, Cambridge, Massachusetts, USA, 2010.

[15] X. Xu, and J.R. Birge "Joint production and financing decisions: Modeling and analysis", Northwestern University Working Paper Series, 2004.

[16] G.C. Reid, "Complex Actions and Simple Outcomes: How New Entrepreneurs Stay in Business.", Small Business Economics, 1999, 303-315

[17] H.R., Varian, "Intermediate Microeconomics: A Modern Approach", W.W. Norton \& Company, 8th Edition, pp 270-286, 2010.

[18] S. Shane, "A General Theory of Entrepreneurship The Individual-Opportunity Nexus", Edwar Elgar Publishing Limited, 1st Edition, 2003.

[19] F. Tanrisever, S. S. Erzurumlu, and N. Joglekar, "Production, Process Investment, and the Survival of Debt-Financed Startup Firms", Production and Operations Management, 2012, 637-652.

Tomczak, Alan, and Alexander Brem. "A conceptualized investment model of crowdfunding." Venture Capital, 2013, 335-359. 